\title{
Factors associated with frailty syndrome in elderly women
}

\author{
Fatores associados à síndrome da fragilidade em mulheres idosas
}

Clóris Regina Blanski Grden ${ }^{1}$, Vanessa Regina de Andrade ${ }^{1}$, Luciane Patrícia Andreani Cabral ${ }^{1}$, Péricles Martim Reche $^{1}$, Erildo Vicente Muller ${ }^{1}$, Pollyanna Kássia de Oliveira Borges ${ }^{1}$

Objective: to evaluate the factors associated with frailty syndrome in elderly women in an outpatient clinic. Methods: cross-sectional study with 252 elderly women. The Mini Mental State Examination and the Edmonton Frail Scale were applied. The association of variables was performed using simple linear regression (Fisher's $\mathrm{F}$ and Student's t tests), $\mathrm{p} \leq 0.05$. Results: there was prevalence of married women (44.4\%) with low schooling (50.0\%) and living with relatives (50.8\%). Among them, $28.6 \%$ had mild, $13.0 \%$ moderate and 3.6\% severe frailty. The factors associated with the syndrome were age $(p=0.021)$, level of education $(p=0.001)$, living with relatives ( $p=0.013)$, illnesses $(p=0.023)$, falls $(p=0.001)$ and hospitalization in the last 12 months $(p=0.001)$. Conclusion: evidenced that almost half of the sample presented some type of frailty. Thus, it is important to evaluate this population frequently, considering the associated factors that can contribute to frailty.

Descriptors: Aged; Frail Elderly; Nursing; Geriatric Nursing.

Objetivo: avaliar os fatores associados à síndrome da fragilidade em mulheres idosas de um ambulatório. Métodos: estudo transversal com 252 idosas. Aplicou-se o Mini Exame do Estado Mental e a Escala de Fragilidade de Edmonton. A associação de variáveis foi realizada por meio da regressão linear simples (testes F de Fisher e $t$ de Student), $\mathrm{p} \leq 0,05$. Resultados: predominaram as casadas $(44,4 \%)$, com baixa escolaridade $(50,0 \%)$ e que moravam com familiares $(50,8 \%)$. Entre elas, $28,6 \%$ possuíam fragilidade leve, $13,0 \%$ moderada e 3,6\% severa. Os fatores associados à síndrome foram idade $(\mathrm{p}=0,021)$, nível de escolaridade $(\mathrm{p}=0,001)$, residir com familiares $(p=0,013)$, doenças $(p=0,023)$, quedas meses $(p=0,001)$ e hospitalização nos últimos 12 meses $(p=0,001)$. Conclusão: evidenciou-se que quase metade da amostra apresentou algum tipo de fragilidade. Assim, é importante avaliar frequentemente essa população, considerando fatores associados que podem contribuir para a fragilidade.

Descritores: Idoso; Idoso Fragilizado; Enfermagem; Enfermagem Geriátrica.

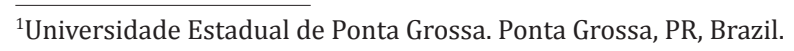




\section{Introduction}

In the last decades the study of frailty has aroused growing interest in the world scientific community. Over the years, it has been observed the evolution and modification of its concept, starting from the model of dependence to the one that contemplates biological and psychosocial aspects.

In the continuing search for a consensus on frailty, experts from six international groups met in the United States to structure an operational definition as well as to outline screening and treatment aspects. The group pointed to frailty as an important medical syndrome with multiple causes and associated factors, characterized by a decrease in the body's capacity for homeostatic reserve and in the resistance to stressors ${ }^{(1)}$.

The said syndrome is indicative of negative clinical outcomes, such as falls, disability, hospitalization and death ${ }^{(1)}$, and represents one of the main causes of morbidity and premature mortality in the elderly ${ }^{(2)}$, with a higher prevalence in females ${ }^{(3-5)}$. Among the causes that contribute to this condition in women, there are the physiological characteristics ${ }^{(5)}$, greater number of diseases ${ }^{(4)}$ and unfavorable economic situation $^{(2)}$, which are considered as stressors that can interfere in the general health status and contribute to the increase of accumulated deficits throughout life.

In the Survey of Health, Aging and Retirement in Europe, conducted with 11,015 elderly aged $\geq 60$ years, living in the community of 11 European Union countries using the criteria of frailty phenotype, it was found that women were almost twice more likely to be frail than men $(16.4 \% \text { vs. } 8.6 \%)^{(6)}$.

National surveys that contemplate conditions associated with frailty in the elderly are scarce ${ }^{(7-8)}$, which justifies the development of studies directed to this population, with emphasis on women, who present a higher risk for the syndrome ${ }^{(6)}$, with repercussions for the loss of functional capacity and autonomy. Thus, the early screening of this syndrome in elderly women will enable health professionals to intervene with measures to delay or attenuate the frailty process in this population. In view of the above, this study aimed to evaluate the factors associated with frailty syndrome in elderly women in an outpatient clinic.

\section{Methods}

This is a cross-sectional study, developed at the Hospital Universitário Regional dos Campos Gerais, in the municipality of Ponta Grossa, Brazil, from October 2015 to March 2016.

The study population consisted of patients on outpatient visit in the institution, with the following inclusion criteria: a) being female; b) being aged 60 years or more; c) having obtained a score higher than the cutoff point in the Mini Mental State Examination $^{(9)}$; and d) being waiting for medical appointment on the day of the interview. Older women with previous diagnoses of diseases that prevented participation in the interviews were excluded.

The convenience sample comprised 280 elderly women, who were interviewed individually while awaiting care in the waiting room of the specialty clinic. After applying the inclusion and exclusion criteria, 252 women participated in the analysis.

The initial stage of data collection included cognitive screening through the Mini Mental State Examination $^{(10)}$. The test consists of 11 items grouped into seven categories, each with the objective of evaluating a group of specific cognitive functions: temporal orientation, spatial orientation, immediate memory, attention and calculation, recall memory, language and visual constructive capacity. The cutoff points were: 13 points for illiterates, 18 for medium and low schooling, and 26 points for high schooling ${ }^{(9)}$.

In order to evaluate frailty, we used the Edmonton Frailty Scale, culturally adapted to the Portuguese language in Brazil ${ }^{(4)}$, which is considered a reliable, valid and easy-to-apply instrument. It contemplates and evaluates nine domains: cognition, general health status, functional independence, social support, medication use, nutrition, humor, continence and function- 
al performance, investigated by 11 items. The maximum score is 17 points, representing the highest level of frailty. Scores for frailty analysis are: $0-4$, no frailty; 5-6, apparently vulnerable; 7-8, mild frailty; 9-10, moderate frailty; and 11 or more, severe frailty ${ }^{(4)}$.

The sample was characterized by the investigation of the following sociodemographic and clinical variables: age; marital status; schooling; household arrangement; financial situation; health problems; medication use; urine loss; and falls and hospitalizations in the last year.

Data were tabulated and analyzed using Stata ${ }^{\circledR}$ software version 12. (StataCorp LP, CollegeStation, TX, USA). Initially, they were submitted to the exploratory analysis and described by measures of frequency, mean and standard deviation. The normality of the data was verified by the Kolmogorov-Smirnov test, which evidenced the assumption of the normal distribution. Still considering the assumptions, residue analyzes were performed and the results revealed that there was no evidence that the homoscedasticity assumption was violated or that a transformation in the answer or explanatory variables was necessary. Later, the association between the independent and dependent variables was verified through simple linear regression with Fisher's F test and Student's t test, using a significance level of $\mathrm{p} \leq 0.05$.

The study complied with the formal requirements contained in the national and international regulatory standards for research involving human beings.

\section{Results}

Among the 252 elderly women interviewed, the mean age was 67.7 years, with a predominance of the age group from 60 to 69 years ( $\mathrm{n}=172,68.2 \%)$, married ( $n=112,44.4 \%)$, with low schooling $(n=126$, $50.0 \%)$ and who lived with relatives $(n=128,50.8 \%)$. Regarding the clinical variables, 248 (98.4\%) elderly women reported having a health problem, 237 (94.0\%) used medication, 119 (47.2\%) reported uri- ne loss, 93 (36.9\%) reported having fallen in the last 12 months and $71(28.2 \%)$ had been hospitalized in the last 12 months (Table 1).

Table 1 - Distribution of elderly women assisted at the specialty outpatient clinic, according to sociodemographic and clinical characteristics

\begin{tabular}{|c|c|}
\hline Variable & n(\%) \\
\hline \multicolumn{2}{|l|}{ Age (years) } \\
\hline 60 to 69 & $172(68.2)$ \\
\hline 70 to 80 & $67(26.6)$ \\
\hline$>80$ & $13(5.2)$ \\
\hline \multicolumn{2}{|c|}{ Marital status } \\
\hline Married & $112(44.4)$ \\
\hline Single & $37(14.7)$ \\
\hline Widowed & $103(40.9)$ \\
\hline \multicolumn{2}{|l|}{ Schooling* } \\
\hline High & $19(7.5)$ \\
\hline Medium & $65(25.8)$ \\
\hline Low & $126(50.0)$ \\
\hline Illiterate & $42(16.7)$ \\
\hline \multicolumn{2}{|c|}{ Household arrengement } \\
\hline Alone & $52(20.6)$ \\
\hline Family & $128(50.8)$ \\
\hline Spouse & $72(28.6)$ \\
\hline \multicolumn{2}{|c|}{ Health problems } \\
\hline Yes & $248(98.4)$ \\
\hline No & $4(1.6)$ \\
\hline \multicolumn{2}{|c|}{ Medication use } \\
\hline Yes & $237(94.0)$ \\
\hline No & $15(6.0)$ \\
\hline \multicolumn{2}{|l|}{ Urine loss } \\
\hline Yes & $119(47.2)$ \\
\hline No & $133(52.8)$ \\
\hline \multicolumn{2}{|c|}{ Falls (in the last 12 months) } \\
\hline Yes & $93(36.9)$ \\
\hline No & $159(63.1)$ \\
\hline \multicolumn{2}{|c|}{ Hospitalization (in the last 12 months) } \\
\hline Yes & $71(28.2)$ \\
\hline No & $181(71.8)$ \\
\hline
\end{tabular}

Regarding the frailty syndrome, 60 (23.8\%) elderly women were considered non-frail, 77 (30.6\%) were apparently vulnerable to frailty, 73 (29.0\%) had mild frailty, 33 (13.0\%) presented moderate frailty and $9(3.6 \%)$ severe frailty. 
There was a statistically significant association between frailty and age $(p=0.021)$, schooling ( $p=0.001)$, living with the family $(\mathrm{p}=0.013)$, satisfactory financial status $(\mathrm{p}=0.001)$, presence of diseases $(\mathrm{p}=0.023)$, loss of urine $(\mathrm{p}=0.001)$ falls in the last twelve months $(\mathrm{p}=0.001)$ and hospitalization in the last twelve months ( $\mathrm{p}=0.001)$ (Table 2).

Table 2 - Mean score in the Edmonton Frailty Scale, simple linear regression coefficient $\beta$ and its confidence intervals $(95 \% \mathrm{CI})$, according to sociodemographic and clinical variables

\begin{tabular}{|c|c|c|c|c|}
\hline Variable & Mean & $\begin{array}{c}\text { Regression } \\
\text { coefficient } \\
\beta^{*}\end{array}$ & $\begin{array}{c}\text { Confidence } \\
\text { Interval } \\
(95 \%)\end{array}$ & $\mathbf{p}^{* *}$ \\
\hline \multicolumn{5}{|l|}{$\overline{\text { Sex }}$} \\
\hline Female & 6.26 & - & - & - \\
\hline Age & - & -0.06 & {$[0.09 ; 0.10]$} & 0.021 \\
\hline \multicolumn{5}{|c|}{ Marital status } \\
\hline Married & 6.53 & - & - & - \\
\hline Single & 6.0 & -0.52 & {$[-1.85 ; 0.79]$} & 0.435 \\
\hline Divorced & 5.45 & -1.07 & {$[-2.19 ; 0.52]$} & 0.062 \\
\hline Widowed & 6.17 & -0.35 & {$[-1.10 ; 0.30]$} & 0.293 \\
\hline \multicolumn{5}{|l|}{ Schooling* } \\
\hline High & 4.0 & - & - & - \\
\hline Medium & 6.09 & 2.09 & {$[0.89 ; 3.28]$} & 0.001 \\
\hline Low & 6.25 & 2.25 & {$[1.12 ; 3.38]$} & 0.001 \\
\hline Illiterate & 7.54 & 3.54 & {$[2.28 ; 4.71$} & 0.001 \\
\hline \multicolumn{5}{|c|}{ Household arrengement } \\
\hline Alone & 5.59 & - & - & - \\
\hline Family & 6.57 & 0.98 & {$[0.21 ; 1.76]$} & 0.013 \\
\hline Spouse & 6.18 & 0.59 & {$[-0.27 ; 1.46]$} & 0.179 \\
\hline \multicolumn{5}{|c|}{ Health problems } \\
\hline Yes & 3.50 & - & - & - \\
\hline No & 6.30 & 1.22 & {$[0.38 ; 5.21]$} & 0.023 \\
\hline \multicolumn{5}{|c|}{ Medication use } \\
\hline Yes & - & - & - & - \\
\hline No & 5.20 & 0.65 & {$[-1.15 ; 2.40]$} & 0.085 \\
\hline \multicolumn{5}{|l|}{ Urine loss } \\
\hline Yes & 5.54 & - & - & - \\
\hline No & 7.05 & 0.29 & {$[0.92 ; 2.08]$} & 0.001 \\
\hline \multicolumn{5}{|c|}{ Falls (in the last 12 months) } \\
\hline Yes & 5.64 & - & - & - \\
\hline No & 7.31 & 0.30 & {$[1.07 ; 2.26]$} & 0.001 \\
\hline \multicolumn{5}{|c|}{$\begin{array}{l}\text { Hospitalization (in the last } \\
12 \text { months) }\end{array}$} \\
\hline Yes & 5.92 & - & - & - \\
\hline No & 7.05 & 1.17 & {$[5.57 ; 6.27]$} & 0.001 \\
\hline
\end{tabular}

\section{Discussion}

As a limitation of the study we can mention the convenience sampling composed of elderly patients who were able to go to the hospital, which may have contributed to the non-inclusion of individuals with higher levels of frailty. Further studies should be conducted with this age group including elderly dependent on caregivers and home visits should be carried out to collect data. This would enable including individuals with lower functional performance and who are unable to reach the health service.

In addition, cross-sectional design was a limiting factor in assessing the causal relationships between the investigated variables and the study outcome. However, cross-sectional studies are relevant for the investigation of chronic conditions such as the frailty syndrome. Also, this type of study is widely used in several national and international surveys.

With regard to the general characterization of the sample, the findings are similar to the results of national surveys about frailty in elderly living in the community ${ }^{(8)}$, institutionalized elderly ${ }^{(11)}$ or in outpatient care ${ }^{(4,12)}$, which indicate average age of 68 years and married status ${ }^{(12)}$, with low schooling ${ }^{(11)}$, who did not live alone ${ }^{(8)}$, who referred diseases ${ }^{(4-5)}$, used medications $^{(12)}$, had suffered falls in the last 12 months and had been hospitalized in the last 12 months ${ }^{(8,12)}$.

The evaluation by the Edmonton Frailty Scale revealed that almost half of the elderly women had some level of frailty, which may be explained by the age of the sample, composed mostly of young elderly women. Similar results were found in cross-sectional research with 166 elderly women, in which $39.2 \%$ of the participants were frail ${ }^{(13)}$. However, the frequency of frailty was significantly higher in comparison to the study that validated Edmonton in Brazil and identified that $31.4 \%$ of the elderly were frail.

The wide variation in the prevalence of physical frailty in epidemiological studies can be attributed to the size and geographic characteristics of the study samples. In view of the risk of apparently vulnerable 
elderly women becoming frail, with repercussions for their quality of life, it is important that the health team performs the early screening of the frailty syndrome.

Some sociodemographic characteristics have been associated with higher levels of frailty, such as age, a variable that is predominant in the older elder$\mathrm{ly}^{(8,14)}$. In this study, this relationship was identified and is in agreement with authors who evaluated the frailty in Brazilian elderly living in the community, by using the Edmonton Scale ${ }^{(4,8)}$. Conditions resulting from the aging process, such as reduced strength, muscle mass and functional reserve, and increased incidence of pathological processes, among others, can corroborate the development of frailty.

Regarding schooling, half of the sample had between one and four incomplete years of study. According to the Brazilian Institute of Geography and Statistics, the elderly are the age group with the highest incidence of illiteracy $(25.7 \%)$ and the one with the lowest average number of years of study among the employed population ${ }^{(15)}$, a condition that may contribute to their vulnerable status.

In this study, we verified a significant association between schooling and the syndrome. A similar result was pointed out in a recent integrative review of the literature ${ }^{(16)}$ and in the cohort study carried out with 1,933 elderly individuals aged 65 years or older, which identified a higher probability of frailty among the elderly with lower schooling (odds ratio $=2.51$ ) ${ }^{(17)}$.

Regarding the household arrangement, the majority of the elderly lived with the family, which may be justified by the large number of elderly women who presented some level of frailty (mild, moderate or severe), a condition that may require the need for care and/or help in activities of daily living.

This study identified an association between frailty and living with relatives, a result that differs from the cohort study conducted with 1,933 elderly people, whose objective was to estimate the prevalence of physical frailty and to verify the association between the sociodemographic characteristics. That study identified this association among the elderly li- ving alone $\mathrm{e}^{(17)}$. The greater chances of developing the syndrome among participants living with relatives can be attributed to the fact that these elderly already present some type of dependence (physical, financial or psychological), which can contribute or accelerate the process of frailty.

The financial variable has been associated with frailty in the same way that national research with elderly people living in the community ${ }^{(8)}$. Although the results are related to satisfactory income, the elderly with low or insufficient income usually have poorer health conditions and are more frail ${ }^{(18)}$.

Almost all of the elderly women interviewed reported having health problems, in the same way as national investigations with the elderly ${ }^{(4-5)}$. Among the several clinical factors associated with the frailty syndrome, the presence of diseases is one of the most reported in the literature ${ }^{(2,4)}$. The presence of diseases affects the health status of the elderly, which can accelerate the appearance of frailty, since such changes in the health status require that the body use available resources, which can lead to the exhaustion of organic reserves ${ }^{(13)}$. The nursing team should stimulate and orient the elderly to the regular practice of physical activity with the goal of maintaining muscle mass and functional capacity.

The variable urine loss was verified in almost half of the elderly and was associated with frailty. Likewise, cross-sectional research with elderly women living in the community identified this condition in $40.9 \%$ of the participants ${ }^{(19)}$. In the integrative review of the literature authors highlight urinary incontinence as a factor associated with the syndrome ${ }^{(16)}$, with repercussions for performance in daily life activities, predisposing the elderly to become less active.

For the clinical conditions falls and hospitalization in the last 12 months, most of the elderly women answered negatively, however, such variables were shown to be associated with the frailty syndrome. A similar result was identified in the cross-sectional study with 511 non-institutionalized elderly people, who found statistical association between the syndrome 
and falls $(\mathrm{p}<0.000)$ and hospitalization in recent months $(\mathrm{p}<0.000)^{(8)}$.

With advanced age, changes in strength and muscle mass, polypharmacy and reduced physical activities may contribute to falls in the aging population. It should be emphasized that older women are more vulnerable to falls due to greater longevity, sedentary lifestyle, medication use, incapacitating chronic diseases and predisposition to sarcopenia. Thus, it is important that nurses perform the early identification of the elderly at risk of falling, as well as the prevention of this adverse event.

It was found in this study that the highest mean score in the Edmonton Frailty Scale occurred in elderly women who had reported hospitalization in the last 12 months. Similar findings were found in a follow-up survey of 515 elderly living in the community, which revealed that for each point increased in the 2013 frailty scale, the chance of hospitalization increases by 1.24 times $^{(11)}$ and a cohort study of 993 elderly individuals aged 70 years or older reported an increased risk of hospitalization by 1.7 times $^{(20)}$.

Hospitalization is often accompanied by a decline in functional status and changes in the quality of life of the elderly. Thus, this condition is an aggravating factor for frailty and, in some cases, a consequence of this syndrome. Thus, it is necessary to reduce hospitalizations due to preventable causes, with emphasis on the prevention of hospital complications.

The present study contributes to the identification of factors associated with frailty, especially in women, which will enable the health team to plan prevention and health promotion actions for this population with a view to preventing the condition of frailty and/or minimization of its consequences, thus favoring a better quality of life in this age group.

\section{Conclusion}

This study made it possible to evaluate the factors associated with the frailty syndrome in elderly women in an outpatient clinic and it was evidenced that almost half of the sample presented some type of frailty. Thus, it is important to evaluate this population frequently, considering associated factors that can contribute to frailty.

\section{Collaborations}

Grden CRB, Andrade VR and Cabral LPA contributed to the conception, analysis, interpretation of data, writing of the article and final approval of the version to be published. Reche PM contributed to the analysis and interpretation of data. Muller EV and Borges PKO contributed to the relevant critical review of intellectual content.

\section{References}

1. Morley JE, Vellas B, Kan GAV, Anker SD, Bauer JM, Bernabei R, et al. Frailty consensus: a call to action. JAMDA. 2013; 14(6):392-7. doi: http:// dx.doi. org/10.1016/j.jamda.2013.03.022

2. Dent E, Kowal P, Hoogendijk EO. Frailty measurement in research and clinical practice: a review. Eur J Intern Med. 2016; 31:3-10. doi: http://dx.doi.org/10.1016/j.ejim.2016.03.007

3. Fabrício-Wehbe SCC, Cruz IR, Haas VJ, Diniz MA, Dantas RAS, Rodrigues RAP. Reproducibility of the Brazilian version of the Edmonton Frail Scale for elderly living in the community. Rev Latino-Am Enfermagem. 2013; 21(6):1330-6. doi: http:// dx.doi.org/10.1590/0104-1169.2933.2371

4. Freitas CV, Sarges ESNF, Moreira KECS, Carneiro SR. Evaluation of frailty, functional capacity and quality of life of the elderly in geriatric outpatient clinic of a university hospital. Rev Bras Geriatr Gerontol. 2016; 19(1):119-28. doi: http://dx.doi. org/10.1590/1809-9823.2016.14244

5. Perna S, Francis MD, Bologna C, Moncaglieri F, Riva A, Morazzoni P, et al. Performance of Edmonton Frail Scale on frailty assessment: its association with multi-dimensional geriatric conditions assessed with specific screening tools. BMC Geriatr. 2017;17:2-10. doi: http://dx.doi. org/ 10.1186/s12877-016-0382-3 
6. Macklai NS, Spagnoli J, Junod J, Santos-Eggimann B. Prospective association of the SHARE operationalized frailty phenotype with adverse health outcomes: evidence from $60+$ community dwelling Europeans living in 11 countries. BMC Geriatr [Internet]. 2013 [cited 2015 Dec 13]; 13(3):1-11. Available from: https://www.ncbi. nlm.nih.gov/pubmed/23286928

7. Santos PHS, Fernandes MH, Casotti CA, Coqueiro RS, Carneiro JAO. The profile of fragility and associated factors among the elderly registered in a Family Health Unit. Ciênc Saúde Coletiva 2015; 20(6):1917-24. doi: http://dx.doi. org/10.1590/1413-81232015206.17232014

8. Carneiro AJ, Ramos GCF, Barbosa ATF, Mendonça JMG, Costa FM, Caldeira AP. Prevalence and factors associated with frailty in noninstitutionalized older adults. Rev Bras Enferm. 2016; 14(6):3927.doi:http://dx.doi.org/10.1590/00347167.2016690304i

9. Bertolucci PHF, Brucki SMD, Campacci SR, Juliano Y. The Mini-Mental State Examination in a general population: impact of educational status. Arq Neuropsiquiatr. 1994; 52(1):1-7. doi: http://dx. doi.org/10.1590/S0004-282X1994000100001

10. Folstein MF, Folstein SE, McHugh PR. "Minimental state": a practical method for granding the cognitive state of patients for the clinican. J Psychiatr Res. 1975; 12(3):189-98. doi: http:// dx.doi.org/10.1016/0022-3956(75)90026-6

11. Fabrício-Wehbe SCC, Rodrigues RAP, Hass VJ, Fhon JRS, Diniz MA. Association of frailty in hospitalized and institutionalized elderly in the communitydwelling. Rev Bras Enferm. 2016; 69(4):6916.doi:http://dx.doi.org/10.1590/00347167.2016690411i

12. Meira AS, Batista MA, Pereira RMP, Rodrigues RAP, Fhon JR, Kusumota L. Frailty in elderly patients with chronic kidney disease under conservative treatment. Rev Rene. 2016; 17(3):38692. doi: https://doi.org/10.15253/21756783.2016000300012

13. Duarte MCS, Fernandes MGM, Rodrigues RAP, Nóbrega MML. Frailty, illness and functional capacity in older women. Rev Enferm UERJ. 2016; 24(2):e6801. doi: http://dx.doi.org/10.12957/ reuerj.2016.680
14. Mata FAF, Pereira PPS, Andrade KRC, Figueiredo ACMG, Silva MT, Pereira MG. Prevalence of frailty in Latin America and the Caribbean: a systematic review and meta-analysis. PLoS One. 2016; 11(8):e0160019. doi: https://doi.org/10.1371/ journal.pone.0160019

15. Instituto Brasileiro de Geografia e Estatística. Síntese de Indicadores Sociais. Uma análise das condições de vida da população brasileira 2016 [Internet]. 2016 [citado 2017 fev 14]. Disponível em:http://biblioteca.ibge.gov.br/visualizacao/ livros/liv98965.pdf

16. Maciel GMC, Santos RS, Santos TM, Menezes RMP, Vitor AF, Lira ABC. Assessment of frailty in elderly people by nurse: integrative review. R Enferm Cent O Min. 2016; 6(3):2430-8. doi: http://dx.doi. org/10.19175/recom.v6i3.1010

17. Sánchez-García S, Sánchez-Arenas R, García-Peña C, Rosas-Carrasco O, Avila-Funes JA, Ruiz-Arregui L, et al. Frailty among community-dwelling elderly Mexican people: prevalence and association with sociodemographic characteristics, health state and the use of health services. Geriatr Gerontol Int. 2014; 14(2):395-402. doi: http://dx.doi. org/10.1111/ggi.12114

18. Guessous I, Luthi JC, Bowling CB, Theler JM, Paccaud F, Gaspoz JM, et al. Prevalence of frailty indicators and association with socioeconomic status in middle-aged and older adults in a swiss region with universal health insurance coverage: a population-based cross-sectional study. J Aging. 2014; 2014:1-8. doi: http://dx.doi. org/10.1155/2014/198603

19. Carvalho MP, Andrade FP, Peres W, Martinelli T, Simch F, Orcy RB, et al. The impact of urinary incontinence and their associated factors in elderly women. Rev Bras Geriatr Gerontol. 2014; 17(4):721-30. doi: http://dx.doi. org/10.1590/1809-9823.2014.13135

20. Martínez-Reig M, Ruano TF, Sánchez MF, García AN, Rizos LR, Soler PA. Frailty and long term mortality, disability and hospitalisation in Spanish older adults. The FRADEA Study. Rev Esp Geriatr Gerontol. 2016; 51(5):254-9. doi: http://dx.doi. org/ 10.1016/j.regg.2016.01.006 